\title{
Hypokinetic-rigid extrapyramidal side effects of neuroleptics: the relationship of the silent period in EMG and HVA and 5-HIAA in CSF
}

\author{
O YAZICI, A HIZAL, L EROĞLU, A BASLO, J YAZICI
}

From the Departments of Psychiatry, Pharmacology, Neurology, University of Istanbul, Capa-Istanbul, Turkey

SUMMARY The relationship between cerebrospinal fiuid levels of HVA and 5-HIAA and the hypokinetic-rigid symptoms that occurred during oral administration of haloperidol in twenty schizophrenic patients was investigated. Measurement of the silent period in the EMG was used for evaluation of these symptoms. The results support the hypothesis of a positive correlation between the CSF HVA and the hypokinetic-rigid side effect and a negative correlation between the pretherapeutic dopamine turnover and the risk of neuroleptic Parkinsonism.

It is believed that almost all neuroleptics increase intracerebral catecholamine turnover and show their action by decreasing the catecholamine-ergic transmission. ${ }^{1}$ It is, however, possible to classify the clinical effects of neuroleptics in two groups: therapeutic (sedative and antipsychotic) effects, and motor (hypokinetic-rigid and hyper-(dys)-kinetic) side effects. ${ }^{2}$ At present the biochemical changes underlying these effects are far from being understood. Even the mechanism of the hypokinetic-rigid effects, which, because of their close resemblance to Parkinson's disease, are likely to be the most understandable of all the clinical effects of neuroleptics, cannot be considered sufficiently clarified at present. ${ }^{2}$

In this study, our intention was the quantitative evaluation of the hyperkinetic-rigid effects of neuroleptics through the measurement of the silent period in EMG, and the investigation of the relationship between silent period and CSF, HVA, 5-HIAA values.

Address for reprint requests: Dr O Yazici, Department of Psychiatry, University of Istanbul, Turkey.

Received 18 December 1984 and in final revised form 7 August 1985. Accepted 8 August 1985

\section{Material and methods}

Thirty schizophrenic patients, diagnosed by using Research Diagnostic Criteria, and found to be normal on general and neurological examination, were hospitalised. Administration of neuroleptics had been stopped at least 2 weeks before the admission. For the purpose of avoiding individual variation, ${ }^{3}$ each patient's unmedicated values ( 0 -state) were used as his own control and compared to the values obtained after one-week (1-state) and two-weeks (2-state) of neuroleptic treatment.

In order to assess the "control-line", the measurements of silent period in EMG were made and HVA, 5-HIAA and probenecid levels in CSF were evaluated after one week of drug-free hospitalisation. On the day of lumbar puncture, the patients were given $4 \mathrm{~g}$ of probenecid orally $(4 \times 1$ $\mathrm{g} /$ hour) and after a period of 8 hours, in which the patient was kept in bed, a sufficient amount of CSF was taken by lumbar puncture and immediately frozen to be analysed within 3-7 days.

On the next day, haloperidol $(3 \times 2 \mathrm{mg} /$ day, by mouth) administration was started and the same procedure was replicated on the 7th and 14th days of the medication.

The acute dystonic attacks which were seen in some of the cases during the first week, were immediately relieved by 3-piperidino-1-phenyl-1-bicycloheptenyl-propanol-1lactat, $0.005 \mathrm{~g}$, IV. Patients were all kept on a standard hospital diet and foods that were rich in catecholamine and 5-HT were excluded. The HVA and the 5-HIAA in CSF were measured spectrofluorometrically, by the methods of Pullar et $a l^{4}{ }^{4}$ and Korf et $a l^{5}$ respectively. The Tillson et al ${ }^{6}$. method 
was used for the spectrophotometric measurement of probenecid.

The silent period in EMG was produced by supramaximal stimulation of the plexus brachialis at the Erb point and was recorded from the biceps muscle with concentric needle electrodes. In order to provide an isometric contraction the subjects were asked to fix their elbows in a $90^{\circ}$ angle with a 1.5 kg weight in their hands. ${ }^{78}$ The silent period was measured as the interval between the electrical stimulation and the onset of uninterrupted muscle activity (the S-X interval). ${ }^{78}$

Ten of the patients were excluded from the study because of missing values or due to the great variance in the probenecid levels. Thus, the data of 20 cases (seven women, 13 men; mean age $26 \pm 3 \cdot 7$ ) were evaluated statistically by regression and partial correlation tests.

\section{Results}

(1) Changes in silent period, $H V A$, 5-HIAA and $P B$ values in respect to time:

In silent period values, a significant increase from the base-line value was established at the end of the first week.

$$
\begin{aligned}
& \mathrm{SP}_{1-0}(r=0.45, \mathrm{p}<0.05) \\
& \mathrm{SP}_{2-1}(\mathrm{r}=0.29, \mathrm{NS})
\end{aligned}
$$

HVA values showed an increase in the first week and a tendency to decrease to the base-line level in the second week; but neither of the changes achieved a significant level.

$$
\begin{aligned}
& \operatorname{HVA}_{1-0}(r=0.32, \mathrm{NS}) \\
& \text { HVA }_{2-1}(r=-0.21, \mathrm{NS})
\end{aligned}
$$

Compared to the control values, there were no significant changes in 5-HIAA and PB values in the first and the second weeks.

5-HIAA - $_{1-0}(r=0 \cdot 15, \mathrm{NS}) \mathrm{PB}_{1-0}(\mathrm{r}=0 \cdot 28, \mathrm{NS})$

5-HIAA $2-1(\mathrm{r}=0 \cdot 10, \mathrm{NS}) \mathrm{PB}_{2-1}(\mathrm{r}=-0 \cdot 19$, NS)

\section{(2) Silent period-HVA and 5-HIAA relations}

There seemed to be a slight but significant relationship between the silent period and dopamine turnover (HVA in CSF) at the end of the first week.

$$
\mathrm{SP}_{1}-\mathrm{HVA}_{1}(\mathrm{r}=0.42, \mathrm{p}<0.05)
$$

This relation did not seem to be due to the probenecid blockade differences, because probenecid values supplied little explanation (RSQ: 0.02) for this relation, and the significance of the relationship was not affected when probenecid levels were kept "constant" by partial correlation test. However, this relationship was not found at the end of the second week. And there were no correlations between silent period and 5-HIAA values in the first and second weeks.

(3) The importance of individual (baseline, control) values

When the place and importance of pretreatment (indi- vidual) values in the results were investigated, two significant relations were found: the first was the significant relationship between the differences of HVA at the end of the first week from base-line $\left(\mathrm{HVA}_{1}-\mathrm{HVA}_{0}\right)$ and the pretreatment HVA levels $\left(\mathrm{HVA}_{0}\right)$.

$$
\left(\mathrm{HVA}_{1}-\mathrm{HVA}_{0}\right)-\left(\mathrm{HVA}_{0}\right) \mathrm{r}=-0.53 \mathrm{p}<0.02
$$

Second, the increments in silent period and HVA from their control values showed a significant positive relationship in the first week.

$$
\left(\mathrm{SP}_{1}-\mathrm{SP}_{0}\right)-\left(\mathrm{HVA}_{1}-\mathrm{HVA}_{0}\right) \mathrm{r}=0.55, \mathrm{p}<0.02
$$

(4) The effects of sex and age on all the results were investigated and no significant relationship could be found. Since our group was composed of young subjects, we could not find any evidence to support the view that "elderly and middle aged people are more at risk of developing Parkinsonian side effects".

(5) The hypokinetic-rigid effects were seen in all of the patients, in varying degrees after the application of neuroleptic. With the object of avoiding subjectivity and the complexity of multiple criteria, we did not attempt to evaluate these manifestations with a scale, other than with the silent period measurement. However, recordings of our observations suggested a correlation between the silent period value and the neuroleptic Parkinsonism.

(6) The acute dystonic attacks after neuroleptic medication occurred in seven patients and mostly on the 3rd day (on the evening of the 2nd day in two patients; on the 3rd day in three patients; on the 4th day in one patient and on the 6th day in one patient). Though it is difficult to make a useful comparison because only three of these patients were included in the final evaluation, we can mention that the group which developed acute dystonic attacks did not show a difference in their CSF HVA and 5 HIAA levels from the others. This seems to be a point which should be further investigated.

\section{Discussion}

Chase et $a l^{9}$ found that CSF HVA level was much lower in the group with extrapyramidal side effects after at least one year of neuroleptic usage and suggested that extrapyramidal side effects might have been related to a dopaminergic neuronal damage caused by neuroleptics. Crowly et al reported that the risk of extrapyramidal side effects development was higher in patients who have low urinary free dopamine prior to neuroleptic administration. 130th 
Annual Meeting of the American Psychiatric Association, 2-6 May 1977.

Van Praag and Korf found that the occurrence of hypokinetic-rigid symptoms showed a positive correlation with the increase in CSF HVA accumulation after probenecid, and a negative correlation with the pretherapeutic HVA response to probenecid. In other words, the risk of neuroleptic Parkinsonism increases in proportion to the lowness of the pretherapeutic dopamine turnover level. ${ }^{10}$

It has been reported that the electromyographic silent period was prolonged in patients with Parkinsonism and that this was shortened during the period of clinical improvement as a result of levodopa treatment. ${ }^{78}$ Though some questions were also raised in respect to the correlation between the silent period and rigidity, ${ }^{7}$ our findings suggest that when the hypokinetic rigid syndrome occurs clinically, silent period values show a parallel increase and dopamine turnover show first a (compensatory) increase, followed later by a tendency to subside. In the first week, the suggestion of a positive correlation between the CSF HVA and the hypokinetic-rigid side effect is supported by our $\mathrm{SP}_{1}$-HVA $\mathrm{A}_{1}$ and $\left(\mathrm{SP}_{1}-\mathrm{SP}_{0}\right)$ $\left(\mathrm{HVA}_{1}-\mathrm{HVA}_{0}\right)$ relationships. In addition to this, the finding of a negative relationship between the baseline HVA and the increment rate of HVA from baseline level, corresponds with the view of a negative correlation between the pretherapeutic dopamine turnover and the risk of neuroleptic Parkinsonism.

As a result, it is possible to consider that our findings support the results obtained by Van Praag and Korf, and also pose the question of the possible importance of the application of silent period measurement in the evaluation and prediction of hypokinetic-rigid side-effects due to neuroleptic drugs.

\section{References}

${ }^{1}$ Praag HM van. Neuroleptics as a guideline to biological research in psychotic disorders. Compr Psychiatry 1975;16:7-22.

${ }^{2}$ Praag HM van. Reduced CA-ergic transmission and clinical effects of neuroleptics. In: Depression and Schizophrenia. New York: Spectrum, 1977:203-11.

${ }^{3}$ Bowers BM Jr. Clinical measurement of central dopamine and 5-Hydroxy-tryptamine metabolism: Reliability and interpretation of cerebrospinal fluid acid monoamine metabolite measures. Neuropharmacol 1972;11:101-11.

${ }^{4}$ Pullar IA, Weddel JM, Ahmed R, Gillingham FJ. Phenolic acid concentrations in the lumbar cerebrospinal fluid of Parkinsonian patients treated with L-dopa. $J$ Neurol Neurosurg Psychiatry 1970;33:851-7.

${ }^{5}$ Korf J, Sikkema TV. Fluorimetric determination of 5-HIAA in human urine and CSF. Clin Chim Acta 1969;26:301-6.

${ }^{6}$ Tillson EK, Schuchardt GW, Fishman JK, Beyer KH. The determination of probenecid (Benemid) in body fluids. $J$ Pharmacol Exp Ther 1954;111:385-95.

${ }^{7}$ McLellan DL. Levodopa in Parkinsonism: reduction in the electromyographic silent period and its relationship with tremor. J Neurol Neurosurg Psychiatry 1972; 35:373-8.

${ }^{8}$ Ertekin C, Aydin A, Kumral K, Kot B. Parkinsonizm' in fizyopatolojisi ve L-dopa. Izmir: Doğruluk Matbaasi 1972:157-85.

${ }^{9}$ Chase TN, Schnur JA, Gordon EK. Cerebral spinal fluig monoamine catabolites in drug-induced extrapyramidab disorders. Neuropharmacol 1970;99:265-8.

${ }^{10}$ Praag HM van, Korf J. The importance of dopamine metabolism for the clinical and side effects of neuroleptics. Am J Psychiatry 1976;133:1171-7. 